\title{
Percepção, tecnologias e subjetividade moderna
}

\author{
Maria Cristina Franco Ferraz ${ }^{1}$ \\ Universidade Federal Fluminense \\ mcfferraz@hotmail.com
}

\begin{abstract}
Resumo: Partindo das recentes teses de Jonathan Crary acerca do processo de modernização da percepção no século XIX, este artigo tematiza o estatuto da imagem e a emergência, na passagem do século $X I X$ ao $X X$, de novos regimes de atenção modulada, vinculados às tecnologias então desenvolvidas. Investiga, a seguir, as implicações desse processo no campo da subjetividade, nas primeiras décadas do século XX, explorando trechos do romance Rumo ao farol, de Virginia Woolf.

Summary: This article takes into account some thesis recently developed by Jonathan Crary, concerning the process of modernization of perception throughout the XIXth century. Emphasis is given to the new status of image and to the emergence of new regimes of modulated attention, connected with the simultaneous development of new technologies of communication. It analyses some implications of this process in what concerns modern subjectivity, in the first decades of the XXth century, exploring some passages of Virginia Woolf's To the Lighthouse.
\end{abstract}

Palavras-chave: modernização da percepção; estatuto da imagem; subjetividade moderna.

Keywords: modernization of perception; image; modern subjectivity.

\footnotetext{
${ }^{1}$ Professora Titular de Teoria da Comunicação da Universidade Federal Fluminense. PósDoutora pelo Instituto Max-Planck de História da Ciência (Berlim). Doutora em Filosofia pela Universidade de Paris 1-Sorbonne.
} 
Para dimensionar de modo mais preciso as mutações por que passa a subjetividade contemporânea, em especial no que concerne à alteração da percepção, da experiência de temporalidade e dos regimes de atenção, vinculada ao desenvolvimento de novas tecnologias comunicacionais e informacionais, proponho um recuo histórico estratégico: investigar as transformações pelas quais passou a percepção no século XIX e seus efeitos sobre novas formas de subjetivação no limiar do século XX. O principal ponto de partida deste trabalho são as teses recentemente elaboradas por Jonathan Crary $^{2}$, elas mesmas diretamente vinculadas, metodológica e conceitualmente, às obras de Michel Foucault e ao horizonte filosófico deleuzeano, como, por exemplo, o método do estabelecimento de conexões transversais entre diversos campos, discursos e práticas. A fim de tematizar o processo de modernização da percepção, privilegiando a passagem do século XIX ao XX, retomemos, inicialmente, a tese central de Crary. Segundo o autor, ao longo do século XIX operou-se uma ruptura radical com relação ao estatuto do observador, esvaziando-se o modelo epistemológico da camera obscura, que teria dominado o pensamento e as práticas dos séculos XVII e XVIII, em favor de um novo modelo epistemológico, vinculado a um outro regime ótico: o do estereoscópio.

De acordo com Crary, a modernização da percepção - inseparável do desenvolvimento e disseminação de transportes mecanizados nas cidades bem como da invenção de novas tecnologias de produção e reprodução de imagens (fotografia, estereoscópio, cinema, por exemplo) - diz respeito a uma mudança radical do sistema ótico e do modelo epistemológico vigentes nos séculos XVII e XVIII, expressos no dispositivo da camera obscura. Nesse sistema e modelo clássico, a produção da imagem estava referida a leis óticas

${ }^{2}$ Cf. Jonathan Crary, Techniques of the observer (Cambridge, Massachusets/Londres: MIT Press, 1990) e Suspensions of perception (Cambridge, Massachusetts/Londres: MIT Press: 1999). 
ligadas a uma física dos raios luminosos (leis de reflexão e refração), de base newtoniana, que prescindiam de qualquer interferência humana, assegurando-se, desse modo, a crença em um sujeito e em um objeto dados a priori, em uma relação de exterioridade, não problemática entre ambos. A rigor, a corporeidade não intervinha: quando emergia, era imediata e rapidamente descartada, como no caso da Dióptrica cartesiana, em que, por exemplo, certa característica potencialmente problemática da visão humana (o fato de termos dois olhos e de apreendermos uma imagem unificada do mundo) só é mencionada para ser imediatamente descartada, através do recurso a uma "glândula pineal" que teria como função sintetizar imagens. Perceber e conhecer o "mundo" era, assim, efeito não apenas de estabilizadoras leis da física mas, em igual medida, de um sujeito presente a si, dotado da capacidade de introspecção e intelecção, um sujeito que tinha na racionalidade um apoio seguro para ter acesso - uma vez eliminados os enganos originados pelo sensível - a um conhecimento e a uma percepção verazes e objetivos. A camera obscura expressava claramente tal perspectiva: as imagens que se projetavam no fundo escuro da câmera, por onde um único orifício deixava penetrar os raios solares, eram efeito de leis naturais que independiam do corpo contingente e cambiante do homem.

Os primeiros sinais que evidenciam a derrocada desse modelo são apontados por Crary na obra de Goethe de 1810: a Farbenlehre, teoria ou doutrina das cores3. Na parte didática que abre essa volumosa obra, Goethe convoca uma experiência no interior da camera obscura que aponta para o esvaziamento tanto do sistema ótico quanto do modelo epistemológico clássico, acima mencionados. Goethe sugere que, no interior da câmera, se fixe a parte iluminada e que, a seguir, uma vez fechado o orifício de entrada dos raios luminosos, se volte os olhos para a escuridão: eles irão vislumbrar uma espécie de imagem circular submetida a um regime de incessantes

3 Cf. Goethe, Zur Farbenlehre, volume 4 (Weimar: H. B. Nachfolger, 1987), bem como Crary, Techniques of the observer, op. cit., especialmente p. 67-69. 
transformações cromáticas. Sugere ainda, mais adiante, que se olhe por algum tempo um objeto colorido, que será retirado da frente dos olhos sem que os mesmos se movam: serão então percebidas cores e luzes, provenientes de uma imagem que pertence, agora, ao próprio corpo. Ou seja: a imagem passa a ser também efeito de um olho, de um corpo que vê, o que acarreta, evidentemente, um forte abalo da certeza com relação ao que se percebe como existente em uma certa exterioridade: a de um "mundo" previamente dado. A partir de então, e de modo cada vez mais radical, não são as puras leis da física dos raios luminosos que presidem à visão, mas o olho, com sua fisiologia própria, que vê um "mundo", ele mesmo doravante não mais tomado como uma exterioridade que possa ser imediatamente apreensível.

Para avaliarmos a extensão desse processo de desestabilização, basta lembrarmos que, no final do século XIX, mais precisamente na década de 1880, o influente Pierre Janet irá propor o significativo conceito de "função de realidade", evidenciando claramente de que forma a "realidade" passou a ser tematizável como efeito de certos regimes de percepção e atenção, de que modo o "real" passou a ser uma "função" de um corpo que vive e dura, afeito, portanto, a todo tipo de variação e distúrbio. Será necessário, então, procurar identificar quando tal "função" efetivamente funciona, quando está perturbada, o que se fará, em geral, a partir da observação do comportamento do indivíduo, o que implica, evidentemente, o enlace, competentemente mostrado por Foucault, entre ciências humanas e “normas”. Quando a própria produção de imagens pode ser desvinculada de um “mundo" exterior, fixado, estável, seguro, desestabilizam-se portanto, simultaneamente, as certezas concernentes tanto ao sujeito quanto ao objeto; no mesmo gesto, o pólo do sujeito se infla, ganhando nova espessura e densidade. Os processos de percepção e conhecimento passam então, necessariamente, a ser alvo de experimentação, observação, descrição e ciência. 
Com efeito, enquanto nos séculos XVII e XVIII o olho (indiferentemente, inclusive, se de um homem ou de um boi ${ }^{4}$ ) era entendido como uma lente e a binocularidade não chegava a se transformar em um problema - o que garantia uma relação de presença e transparência do sujeito ao mundo -, a partir do início do século XIX, com Goethe e, já nas décadas de 20 e 30, com o desenvolvimento da fisiologia óptica e da psicofisiologia, o olho mergulha na opacidade, na materialidade e espessura da corpo humano, com sua inevitável contingência e incontrolável variabilidade5. A imagem passa a ser produto de um olho fisiologicamente complexo, que será cada vez mais remetido ao cérebro, ao sistema nervoso central, em geral compreendido através de analogias tecnológicas, como a do telégrafo ${ }^{6}$. Enquanto na física óptica as cores, por exemplo, eram referidas tão-somente à luz branca que, infletindo-se em graus variados e geometricamente determinados - em função da hipótese newtoniana da "diversa refrangibilidade" - produziam todo o espectro de cores7, no limiar do século XIX Goethe começa por atribuir as cores a uma fisiologia. A parte didática de seu tratado se abre com a sessão “cores fisiológicas", a que se acrescentam duas outras partes, uma física e outra química. Posteriormente, de modo ainda mais radical, Shopenhauer irá remeter as cores exclusivamente à fisiologia do corpo humano. Bastante

4 Cf. Descartes, $A$ dióptrica (1637), citado em Crary, Techniques of the observer, op. cit., p. 47-48.

5 Já em meados do século XIX, vários pesquisadores (dentre os quais o influente Hermann von Helmholtz) estudarão o que chamaram de "fenômenos entópticos" (ou mouches volantes, "moscas voadoras") para descrever e investigar as imagens intra-oculares, ou seja, aquelas que, em algumas situações (como fadiga, por exemplo), um olho "vê", por exemplo, traços fantasmáticos dos vasos sanguíneos ou de partículas constitutivas do próprio tecido ocular (cf. Crary, Suspensions of perception, op.cit, p. 214-216). O olho não apenas se torna corpo, mas, em sua curiosa opacidade, pode chegar até mesmo a vislumbrar elementos de sua própria materialidade. Estamos bem distantes da transparência do olho-lente próprio aos séculos XVII e XVIII.

${ }^{6}$ Crary cita uma passagem de Helmholtz em que o cientista declara: "Nerves have been often and not unsuitably compared to telegraph wires". Cf. Crary, Techniques of the observer, op. cit., p. 93, grifos meus.

7 A esse respeito, ver Dennis L. Sepper, Goethe contra Newton (Cambridge: Cambridge University Press, 1988) e A. I. Sabra, Theories of light - from Descartes to Newton (Cambridge: Cambridge University Press, 1981). 
marcado por Goethe e pelos estudos em psicofisiologia e fisiologia ótica desenvolvidos pelos cientistas entre a primeira e segunda edições de sua obra Mundo como vontade e representação (entre 1819 e 1844, portanto), Shopenhauer radicalizou tal perspectiva, passando a considerar as cores como puro efeito da fisiologia humana.

Uma vez que a visão passa a ser ancorada na corporeidade, novos fenômenos - pós-imagem, persistência retiniana, paralaxe, disparidade binocular - tornam-se mediação incontornável em toda percepção e, conseqüentemente, em toda relação de conhecimento. Muitos dos fisiologistas das primeiras décadas do século XIX, por realizarem pesquisas com a própria visão - como, por exemplo, tentar mapear as pós-imagens, após fixar diretamente a luz solar8 -, terminaram cegos. Esses novos fenômenos pesquisados tornaram-se, com efeito, objeto de investigação intensiva das novas ciências em expansão entre as décadas de 20 e 40 do século XIX (fisiologia óptica e psicofisiologia), bem como, na segunda metade e no final do século, da psicologia científica (com Wundt, por exemplo) e da neurologia nascente, com Sherrington. O processo de modernização da percepção, explorado por Crary, corresponde, em linhas gerais, a um segundo movimento da Modernidade, tal como tratado por Hans Ulrich Gumbrecht ${ }^{9}$, caracterizado por um observador de segundo grau, que volta sua observação sobre si, sobre o próprio corpo, em sua complexa fisiologia. Segundo Jonathan Crary, foi no âmbito dessa ampla mutação de cunho epistemológico que se desenvolveram novas tecnologias ópticas, que, dos laboratórios, migraram para as feiras populares e casas burguesas (taumatrópios, estereoscópios etc), e se inseriram na cultura do espetáculo nascente, vinculada a um novo regime de atenção, que configura um continuum entre a atenção e formas variadas de desatenção,

\footnotetext{
8 Crary cita, por exemplo, o cientista tcheco Jan Purkinje, que procurou diagramar diversas pós-imagens. Cf. Techniques of the observer, op. cit., p. 103.

9 Cf. Gumbrecht, "Cascatas de modernidade", in Modernização dos sentidos (São Paulo: Editora 34, 1998).
} 
devaneio, transe, sonambulismo. Como salienta Crary, as novas formas de "industrialização da contemplação" foram de fato associadas a estados relativos de hipnose e sonambulismo. Jonathan Crary enfatiza de que modo tal suspeita freqüentava de modo explícito as preocupações da sociologia nascente, em especial as reflexões de Gabriel Tarde e de Gustave Le Bon:

Tarde eqüacionou, decididamente, existência social e sonambulismo, ou seja, um estado caracterizado por uma elevada receptividade à sugestão. Le Bon e outros ressaltaram aspectos hipnóticos da vida das multidões, mas Tarde foi mais longe: "Não devo parecer fantasioso ao pensar o homem social como um verdadeiro sonâmbulo... O estado social, como o hipnótico, é apenas uma forma de sonho"10.

A subjetividade moderna se delineia, assim, como extremamente porosa e flutuante, como limiar de diversas flutuações, que irão suscitar tanto a investigação, o exame científico, quanto o controle das tendências dissociativas, sempre presentes, mesmo que de modo latente. A emergência das ciências "psi" encontra-se, assim, totalmente vinculada ao processo de modernização da percepção, também expresso por essa nova configuração da subjetividade, bem como a esse duplo movimento de exame e controle. Como mostrou Foucault, as categorias de "norma" e "desvio", que funcionam em uma lógica elástica de estabelecimento de fronteiras sempre e inevitavelmente moventes, respondem a essa nova plasticidade de que se dota a subjetividade resultante desse processo de modernização, seja no campo epistemológico, seja no campo das práticas da época.

Ao longo do século XIX, portanto, a visão, a percepção e a cognição passam a se ancorar em um solo movente, necessariamente contingente e instável - a corporeidade -, convocando uma nova concepção de subjetividade, pensada (e vivida) como flutuante e modulada. No mesmo movimento, a intensa e inaudita estimulação sensório-motora dos corpos nas cidades em

${ }^{10}$ Cf. Crary, Suspensions of perception, op. cit., p. 242, minha tradução. 
expansão operam uma crescente fragmentação da percepção de "mundo", favorecendo a configuração de um novo tipo de observador, dotado de uma atenção igualmente flutuante, de uma "interioridade" que passou a ser investigada, esquadrinhada e quantificada, para fins de domesticação e “normalização”. Surgidos de diversas experimentações laboratoriais, certos dispositivos ópticos (taumatrópios, estereoscópios etc) serviram de apoio ao estudo e à quantificação de tais fenômenos e, no mesmo passo, mobilizaram e solicitaram novas formas de percepção, novos regimes focados e modulados de atenção. Tais dispositivos também contribuíram, desse modo, para adestrar e reconfigurar o regime de percepção. Enquanto, o modelo de visão anterior - que não a autonomizava nem especificava e fundava-se em uma analogia com o tato - sustentava uma auto-presença do mundo para o observador e ancorava-se na instantaneidade, na imediatez e na natureza atemporal da percepção, a concepção subjetiva da visão levou a uma volatilização da distinção entre novas "patologias" da atenção e estados intensivos e criativos de profunda absorção e devaneio. A temporalidade e uma inevitável ambivalência introduziram-se no âmbito da percepção e dos estados cognitivos. Nesse novo modelo, a percepção humana, condicionada por temporalidades e processos físicos e psicológicos, oferece, no máximo, uma aproximação provisória e instável de seus objetos. Emerge então uma intensa problematização acerca da atenção, que, necessariamente constituída por estados de desatenção, de inibição que a emolduram, inerentemente instável, sujeita ao controle e à patologização, passa a funcionar, segundo Crary, como um modelo de como um sujeito pode sustentar um sentido coerente e prático do mundo. A "realidade", tal como no conceito de Pierre Janet acima mencionado, passa, assim, a ser uma "função" psíquica e fisiologicamente determinada.

Como a produção de imagens passa a estar vinculada à corporeidade, a percepção se abre inexoravelmente a todo tipo de flutuação e descontrole, o que irá convocar práticas intensivas e incessantes de domesticação 
(pedagógicas, científicas) - necessariamente sempre ameaçadas por processos de dissociação. $O$ processo de modernização remete a uma percepção inexoravelmente atrelada a um corpo cinético. A imagem passa a ser efeito e produto de um corpo vivo, humano, com seu modo de funcionamento específico e facilmente afetável. Pós-imagens e cores fisiológicas, por exemplo, não só para Goethe como também para diversos cientistas do século XIX (como os influentes Johannes Müller ${ }^{11}$ e o já mencionado Helmholtz), podem ser produzidas por socos em um olho ou pela ingestão de substâncias alucinógenas. Como mostra claramente a atenção dada ao fenômeno da pósimagem, o que se vê pode ser desreferencializado com relação a algo "exterior" ao homem, podendo estar única e exclusivamente vinculado a um corpo afetado ou estimulado interna ou externamente. No "modelo estereoscópico", o olho passa a produzir imagens, reagindo orgânica e temporalmente a determinados estímulos internos e/ou externos. Cabe lembrar que a temporalidade, a persistência retiniana (então estudada, quantificada e controlada para adequar os corpos a novos regimes perceptivos, à mecanização da produção e à lógica do consumo), o aspecto necessariamente cinético da percepção são elementos inerentes à invenção de uma das mais bem sucedidas tecnologias de produção de imagem surgidas no final do século XIX: o cinema.

Estudando em paralelo as ciências empíricas então nascentes, arte e filosofia finisseculares e diversas tecnologias em pleno desenvolvimento na época, Jonathan Crary ressalta que as mesmas condições que estimularam o impulso cientificizante que procurava desentranhar alguma regularidade dos processos dinâmicos, do puro fluxo inerente à configuração moderna da subjetividade, constituíram o solo escavado e explorado por uma intensa e rica experimentação artística. A arte finissecular fará, com efeito, descobertas sem precedentes sobre a indeterminação da percepção atenta e inventará variados

${ }^{11}$ Cf. Crary, Techniques of the observer, p. 90-91. 
dispositivos de intensificação, apostando na instabilidade para reinventar a experiência perceptiva e renovar as práticas representacionais. Como assinala dessacralizadamente Crary, grande parte das experimentações pictóricas da segunda metade do século XIX (a começar pelas experimentações de Turner) não estará, nesse sentido, apenas em uma oposição de superfície com relação às práticas de domesticação e às ciências, em seu esforço de quantificação e controle, já que, assim como tais práticas e saberes, também irá explorar a visão nessa condição primordial, que marca a modernidade: sua inserção no corpo, na complexidade da "psicofisiologia" humana.

A partir desse horizonte teórico-filosófico, exploremos brevemente o tema da modernização da percepção, da atenção, tal como expresso em uma obra literária dos anos 20 do século passado, momento em que esse processo já tinha se consolidado e intensificado nos corpos dos homens e mulheres modernos. Trata-se do romance Rumo ao farol'12 (1927), De Virginia Woolf. Nesse romance, como aliás em outras obras da autora, as modulações da atenção, o fluxo ondulante da subjetividade (sobretudo feminina) são expressos e enfatizados de modo radical. O próprio texto muitas vezes esposa esse movimento e o intensifica. Em Rumo ao farol, esse movimento se dá em especial através da personagem Sra. Ramsay, uma senhora burguesa em torno da qual gira toda a família e, como o farol do título, o próprio romance. Cabe assinalar que, com freqüência nos estudos literários, se estabelece uma conexão entre a narrativa impressionista de Virginia Woolf e o tema do stream of thought (fluxo de pensamento), de William James. James e Bergson ${ }^{13}$ estão, evidentemente, ligados ao processo aqui discutido. Privilegiarei entretanto, aqui, na esteira de Crary, outro tema, aliás também presente em James: o da atenção.

\footnotetext{
12 Virginia Woolf, To the Lighthouse (Londres: Wordsworth, 2002), e na versão brasileira, traduzida por Luiza Lobo, Rumo ao farol (Rio/São Paulo: O Globo/Folha de São Paulo, 2003). Todas as citações estarão referidas a essa edição brasileira.

${ }_{13}$ Cf. meu artigo "Percepção, imagem e memória na modernidade: uma perspectiva filosófica", Revista da Intercom, volume XXVII, São Paulo: janeiro/junho de 2004.
} 
Retomemos, inicialmente, certa passagem do capítulo XVII da primeira parte do livro: a cena se passa em volta da mesa, em torno de um jantar no qual se reúnem tanto a família Ramsay quanto seus convidados e em que se delineiam certos planos de alianças e casamentos. A Sra. Ramsay, contente com o sucesso do jantar - tanto do prato principal, um trabalhoso "Boeuf en daube”, quanto da agradável sociabilidade estabelecida em torno da mesa -, permite-se então se deixar levar por um regime de atenção esgarçado, por um estado de devaneio que será rompido apenas nos momentos em que sua atenção precisa ser reatada à cena, assegurando sua inserção na cena familiar e seu controle da situação socialmente compartilhada. Leiamos um primeiro fragmento da cena, na qual, após servir o prato do filho mais velho (Andrew), a Sra. Ramsay começa a relaxar, por instantes, sua atenção centrada no jantar:

\begin{abstract}
- Andrew, abaixe o prato ou o entornará (o Boeuf en daube era um completo êxito). - Ali ficava - sentiu, ao pousar a colher - o espaço tranqüilo que descansa próximo ao cerne das coisas, onde se podia andar ou repousar; e agora, era esperar (já servira a todos) e ouvir; depois, semelhante a um falcão que se lança repentinamente das alturas onde estava, podia exibir-se e se entregar ao riso fácil, descansando todo o seu peso no que seu marido dizia, na outra extremidade da mesa, a respeito da raiz quadrada de mil duzentos e cinqüenta e três, que era, por acaso, o número da sua passagem de trem. (p. 112)
\end{abstract}

Notemos que nesse trecho mesclam-se regimes de narração: no começo, temos a transcrição de uma frase da Sra. Ramsay em estilo direto (ela se dirige ao filho mais velho, Andrew), mas, logo a seguir, os parênteses evidenciam uma penetração do narrador na esfera "interna" da personagem, que saboreia o sucesso do jantar e, logo a seguir, uma transcrição ao mesmo tempo de dentro (“Ali ficava ... o espaço tranqüilo que descansa...”) e de fora ("sentiu, ao pousar a colher") da personagem. Cumpridas com discreta eficiência suas funções de dona de casa e anfitriã exemplares, a Sra. Ramsay pode, por frações de segundos, ralentar o ritmo de sua atenção pragmaticamente orientada, para "andar ou repousar" em outro espaço, 
"próximo ao cerne das coisas" 14; ou então para "esperar e ouvir", posto que "já servira a todos". O regime dilatado de percepção e atenção, que introduz alterações espaço-temporais, será cortado como que por uma flexa, retornando a um foco reduzido e achatador da experiência de tempo, movimento precisamente expresso na imagem da rapidez e destreza certeira de um falcão "que se lança repentinamente das alturas onde estava". Descansando de suas funções sociais, tal um falcão, a Sra. Ramsay flutua, em majestoso sobrevôo, em alturas solitárias, mas seu repouso pode ser interrompido de modo repentino, quando algo "embaixo", no solo da vida comum, solicita sua atenção e a força de gravidade da cena familiar a suga em sua direção. Falcão, liga-se tanto às altitudes aladas quanto à corriqueira terra, podendo "descansar seu peso" nas trivialidades ditas, com matiz de pseudo racionalidade, por seu marido, homem de ciências dominador e inseguro. Obviamente, a ironia é flagrante, na distinção entre os vôos efetivos da mulher e os falsos vôos teóricos (totalmente arbitrários e derrisórios) do marido. A mulher que pode "voar", parecer "avoada", o "bovarismo" - traços femininos que, da literatura oitocentista, migram para a cultura (e ciência) da época - são aqui revelados em seu reverso, em um ângulo claramente favorável à mulher, como outra modalidade de experiência perceptiva e cognitiva, muito mais rica. Essa perspectiva é reforçada de modo ainda mais explícito na continuidade da cena:

\footnotetext{
14 No original, "the heart of things".
} 
Que significava tudo aquilo? Até agora, nunca tivera a menor noção. Uma raiz quadrada? Que seria? Seus filhos sabiam. Ela se apoiou neles, e em raízes cúbicas e quadradas. Era disso que falavam agora. [...] Deixou-se amparar pela magnífica estrutura construída pela inteligência masculina, onde esta se movimenta em todos os sentidos, para cima e para baixo, por entre as barras de ferro que se entrecruzam na estrutura oscilante que sustenta o mundo. Assim, ela podia se abandonar a ele completamente; até mesmo fechar os olhos, ou piscá-los um instante, como uma criança ao ver uma árvore de sua cama e observar as milhares de camadas de folhas superpostas. Então acordou. A inteligência masculina ainda se manifestava. (p. 112)

O trecho se inicia em evidente discurso indireto livre ("Que significava tudo aquilo?” etc), mas o narrador toma logo a seguir certa distância (“Deixou-se amparar pela...") e, quase como uma tese, denuncia a fragilidade das pomposas construções com que se pavoneia a "inteligência masculina", que se movimenta em uma "magnífica estrutura" 15, "por entre barras de ferro”. A essa construção que se dá como estável e sólida corresponde (e aqui se podem estabelecer fortes relações com o pensamento de Nietzsche ${ }^{16}$ ) a "estrutura oscilante que sustenta o mundo", de que o regime perceptivo e cognitivo da Sra Ramsay está muito mais próximo. Ela nada sabe acerca de "raízes quadradas ou cúbicas", mas vivencia uma experiência temporal mais rica e matizada, desenraizando-se para poder variar de altura e experimentar diferentes oscilações, planos de vôos, abandonando-se ao fluir incessante do tempo, com ele fundindo-se, podendo alcançar, em um relance, o pulsante “coração das coisas”. Tal movimento de deriva pode vir acompanhado por um fechar ou por um breve piscar de olhos, dando acesso à riqueza singular de todas as coisas: "como uma criança ao ver uma árvore de sua cama e observar as milhares de camadas de folhas superpostas". Lembremos, aqui, o conto "Funes, o memorioso", de Borges, em que, paralisado em sua cama, o

\footnotetext{
${ }^{15}$ No original, "admirable fabric", que também pode ser traduzido como tecitura, tecido, o que remete o termo (e, portanto, essa passagem) ao sentido etimológico da palavra "texto". Cf., a esse respeito, o capítulo "Da valorização estratégica da metáfora em Nietzsche", em meu livro Nove variações sobre temas nietzschianos (Rio: Relume Dumará, 2002).

${ }^{16}$ Cf. o capítulo "Da valorização estratégica da metáfora em Nietzsche", em idem, ibidem.
} 
personagem é invadido pela percepção extrema da radical singularidade e diferença de cada folha da árvore que vê pela janela, a cada instante do dia. Ao que tudo indica, portanto, a concepção modulada da subjetividade, inerente ao processo de modernização da percepção, revela, aqui como em outros filósofos e $\operatorname{artistas}^{17}$, sua potência como meio de acesso ao "cerne das coisas", concebidas como puro movimento de variação e diferenciação, como meio de alcançar outra esfera ontológica.

O estado de devaneio que infla a experiência do tempo e permite aceder a uma nova apreensão das coisas, mais intensa e fundamental, assemelha-se, como se pode constatar no trecho citado, ao sono ou ao transe. Passado tal momento, o narrador acrescenta, em uma frase curta, tão abrupta quanto a própria alteração do regime de atenção: "Então acordou.” E ainda acrescenta, ampliando o efeito de humor (com relação ao mundo dos homens) da passagem: "A inteligência masculina ainda se manifestava." Toda essa cena culmina, a seguir, na seguinte passagem:

${ }^{17}$ Crary enfatiza, em seu livro Suspensions of perception, uma exploração análoga da potência ontológica das modulações da percepção, em especial a "reivenção de sínteses", na obra tardia de Paul Cézanne. 


\begin{abstract}
Agora já não precisava ouvir. Sabia que isso não poderia durar, mas no momento seus olhos estavam tão límpidos que pareciam circular pela mesa desvendando o interior das pessoas, seus pensamentos e seus sentimentos, sem esforço, como uma luz que penetra furtivamente sob a água e ilumina os juncos imersos, os barrigudinhos se movendo e a truta rápida e silenciosa, em todo o seu frêmito e em todas as suas ondulações. Era assim que os via e ouvia; mas tudo o que diziam também tinha essa capacidade de se assemelhar ao movimento de uma truta, quando a ondulação da água e o cascalho do fundo, alguma coisa à direita e à esquerda, são percebidos de um só relance; pois - enquanto na vida ativa ela unia e dissociava uma coisa da outra, afirmava que gostava dos romances de Scott ou que não os tinha lido, sentindose pressionada a ir adiante - agora ela não dizia nada. No momento permanecia em suspenso. (p. 113)
\end{abstract}

O movimento de suspensão ganha, aqui, contornos aquáticos e ondulantes ${ }^{18}$. A ação e a fala se interrompem e suspendem. A Sra. Ramsay, consciente do caráter excepcional e fugaz desse movimento de deriva ("Sabia que isso não poderia durar") - movimento que se instala justamente na “duração" bergsoniana - se esquiva da pressão social ("já não precisava ouvir”); então, seu novo olhar, límpido e penetrante, circula pela mesa e desvela (no original, "unveil") cada uma das pessoas à volta da mesa, penetrando-as sem esforço. Cabe assinalar que à pressão ("enquanto na vida ativa [...], sentindo-se pressionada a ir adiante”), ao esforço de atenção inerente às demandas sociais parece corresponder a necessidade de escapar, de alçar vôo ou navegar em outra dimensão temporal. Tanto maiores as demandas de controle (tal como sobre as mulheres no limiar do século XX) tanto mais potente a força da fuga. Tal movimento é ao mesmo tempo controlado pela consciência e dela liberto. As metáforas são, agora, não mais aéreas e aladas, mas luminosas e aquáticas. Ou melhor: fusão de ambas, luz penetrando em água. Ao falcão se substitui a truta "rápida e silenciosa": a Sra. Ramsay não mais voa ou sobrevoa a cena, mas mergulha em outra dimensão espaço-temporal, em outro regime de atenção, desfocado para a vida pragmática mas curiosamente desperto e penetrante com relação a outro

18 Obviamente, as ondas, os movimentos ondulantes são forças que atravessam os textos de Virginia Woolf, autora igualmente do romance The waves. 
plano, a um plano submerso. As sensações se embaçam, arrastadas por esse irresistível movimento da subjetividade-truta, que atravessa, com sua luz, as águas, contaminando a cena e nela se espraiando: "tudo o que diziam também tinha essa capacidade de se assemelhar ao movimento de uma truta”. Ao olhar atento para as vicissitudes da vida comum se substitui um olhar penetrante, veloz, fremente, instantâneo: "alguma coisa à direita e à esquerda, são percebidos de um só relance”. Eliminada a pressão, a sucção e força de gravidade da cena social, a fala pode, enfim, ceder lugar a um silêncio de águas correntes e transparentes, de peixes ágeis, velozes. Sua percepção é dupla, oscilante: ao mesmo tempo que pode ver as pessoas e ouvir as conversas, permanece em estado de quase transe, de absorção e certo sonambulismo, embalada pela breve mas intensa libertação expressa nessa experiência.

Quando lemos esses trechos e o belo romance de Virginia Woolf, podemos perceber que, tal como em determinados filmes de Ingmar Bergman ("Persona", por exemplo) ou mesmo do Woody Allen dos anos 70 e 8o, de certo modo essas condições subjetivas, a temporalidade densa a que correspondem (tão bem expressas no conceito bergsoniano de duração), o interesse pelos meandros da "interioridade" parecem atualmente deslocar-se em favor de novos modos de subjetivação, ligados a outras temporalidades (mais imediatas e instantâneas) ${ }^{19}$, a outros comportamentos e outras práticas tecnologicamente mediadas. O modo de subjetivação produzido pelo longo processo de modernização aqui tematizado revela-se claramente em certas produções e experiências do século XX, século em que a subjetividade moderna, psicologicamente constituída, parece ter conhecido seu apogeu. $\mathrm{Na}$ virada do século XX ao XXI, vários elementos apontam para um paulatino esvaziamento dessa configuração da subjetividade. Conforme diversos autores assinalam, assistimos a uma tendência crescente a um declínio da

19 Lembremos o tema do "colecionador de sensações instantâneas", desenvolvido por Zigmunt Bauman, como uma das figuras da contemporaneidade. 
interioridade ${ }^{20}$, vinculada a um processo progressivo de "somatização" e externalização do "eu", tanto nas práticas quanto nos saberes contemporâneos. Retornando ao século XIX, podemos observar talvez com maior pecisão as velozes mudanças de que somos contemporâneos e que, necessariamente, afetam o regime de percepção, a vivência do tempo, bem como as relações com os outros, com o próprio corpo e o "eu".

\footnotetext{
${ }^{20}$ A esse respeito, conferir o breve e iluminador artigo de Benilton Bezerra Júnior, intitulado "O ocaso da interioridade e suas repercussões sobre a clínica", publicado em Plastino (org.), Transgressões (Rio: Contra Capa/Rios Ambiciosos, 2002. Ressalte-se o tema da espetacularização da saúde na superfície dos corpos.
} 


\section{REFERÊNCIAS BIBLIOGRÁFICAS:}

BAUMAN, Zigmunt. O mal-estar da pós-modernidade. Rio de Janeiro: Jorge Zahar, 1998.

BERGSON, Henri. Oeuvres. Paris: PUF, 2001.

BEZERRA, Benilton. "O ocaso da interioridade e suas repercussões sobre a clínica”. IN: PLASTINO (org.). Transgressões. Rio: Contra Capa/Rios Ambiciosos, 2002.

BORGES, Jorge Luis. Ficções. São Paulo: Ed. Globo, 1997. CHARNEY, Leo e SCHWARTZ, Vanessa (org.). O cinema e a invenção da vida moderna. São Paulo: Cosac \& Naify Edições, 2001.

CRARY, Jonathan. Suspensions of perception (attention, spectacle, and modern culture). Cambridge, Massachusetts/Londres: MIT Press, 1999.

Techniques of the observer (on vision and modernity in the XIXth century). Cambridge, Massachusetts/Londres: MIT Press, 1990. FERRAZ, M. C. Franco. Nove variações sobre temas nietzschianos. Rio de Janeiro: Relume Dumará, 2002.

. "Percepção, imagem e memória na modernidade: uma perspectiva filosófica”. Revista da Intercom, volume XXVII. São Paulo: janeiro/junho de 2004.

. "Sociedade tecnológica: de Prometeu a Fausto". Revista

Contracampo, número 4. Niterói: IACS/UFF, 2000.

FOUCAULT, Michel. História da sexualidade I (a vontade de saber). Rio de Janeiro: Graal, 1977.

GOETHE. Zur Farbenlehre, Volume 4. Weimar: H. B. Nachfolger, 1987. GUMBRECHT, Hans Ulrich. A modernização dos sentidos. São Paulo: Ed. 34, 1988.

JAMES, William. The Principles of Psychology.

Chicago/Londres/Toronto: Encyclopaedia Britannica, Inc., 1952. 
SABRA, A. I. Theories of light (from Descartes to Newton). Cambridge: Cambridge University Press, 1981.

SEPPER, Dennis L. Goethe contra Newton (polemics and the project for a new science of colour). Cambridge: Cambridge University Press, 1988.

WOOLF, Virginia. Rumo ao farol. Tradução de Luiza Lobo. Rio/São Paulo: O Globo/Folha e São Paulo, 2003. 